
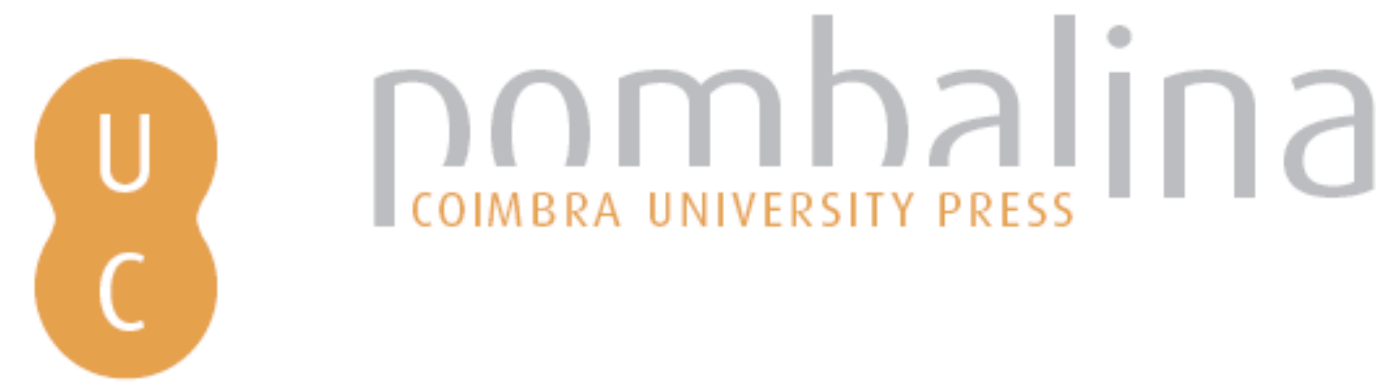

\title{
Geogestão aplicada ao espaço universitário: características do espaço arquitetônico facilitadoras do aprendizado
}

Autor(es): $\quad$ Choas, Mona Lisa Lobo de Souza; Bezerra, Maria do Carmo de Lima

Publicado por: Imprensa da Universidade de Coimbra

URL

persistente: URI:http://hdl.handle.net/10316.2/37090

DOI: $\quad$ DOI:http://dx.doi.org/10.14195/978-989-26-0983-6_38

Accessed : $\quad$ 26-Apr-2023 13:37:55

A navegação consulta e descarregamento dos títulos inseridos nas Bibliotecas Digitais UC Digitalis, UC Pombalina e UC Impactum, pressupõem a aceitação plena e sem reservas dos Termos e Condições de Uso destas Bibliotecas Digitais, disponíveis em https://digitalis.uc.pt/pt-pt/termos.

Conforme exposto nos referidos Termos e Condições de Uso, o descarregamento de títulos de acesso restrito requer uma licença válida de autorização devendo o utilizador aceder ao(s) documento(s) a partir de um endereço de IP da instituição detentora da supramencionada licença.

Ao utilizador é apenas permitido o descarregamento para uso pessoal, pelo que o emprego do(s) título(s) descarregado(s) para outro fim, designadamente comercial, carece de autorização do respetivo autor ou editor da obra.

Na medida em que todas as obras da UC Digitalis se encontram protegidas pelo Código do Direito de Autor e Direitos Conexos e demais legislação aplicável, toda a cópia, parcial ou total, deste documento, nos casos em que é legalmente admitida, deverá conter ou fazer-se acompanhar por este aviso. 


\section{$\forall$ \\ TAS DAS I JORNADAS LUSÓFONAS DE CIÊNCIAS E TECNOLOGIAS DE INFORMAÇÃO GEOGRÁFICA}

Editores

José Gomes dos Santos

Cidália Fonte

Rui Ferreira de Figueiredo

Alberto Cardoso

Gil Gonçalves

José Paulo Almeida

Sara Baptista 


\title{
ARTIGO 38
}

\section{GEOGESTÃo APLICADA AO ESPAÇO UNIVERSITÁrio: CARACTERÍSTICAS DO ESPAÇO ARQUITETÔNICO FACILITADORAS DO APRENDIZADO}

CHOAS, Mona Lisa Lobo de Souza ${ }^{1}$ E BEZERRA, Maria do Carmo de Lima. ${ }^{2}$

\begin{abstract}
${ }^{1}$ Centro de Pesquisa em Arquitetura da Informação - Faculdade de Ciência da Informação da Universidade de Brasília (Brasil) Centro de Pesquisa em Arquitetura da Informação, Faculdade de Ciência da Informação Campus Universitário Darcy Ribeiro, Instituto Central de Ciências - ICC, Bl. B Subsolo Centro, Asa Norte, Brasília, Brasil Tel: +55 61 31076318; e-mail: arqmona05@gmail.com

2 Faculdade de Arquitetura e Urbanismo - Universidade de Brasília, Faculdade de Arquitetura e Urbanismo Campus Universitário Darcy Ribeiro, Instituto Central de Ciências - ICC, B1. B Subsolo Centro, Asa Norte, Brasília, Brasil Tel: +55 61 32570406; e-mail: macarmo@unb.br
\end{abstract}

\section{RESUMO}

$\mathrm{O}$ artigo aborda características do espaço arquitetônico facilitadoras do aprendizado em instituições de nível superior e seu armazenamento em sistema de informações para gerenciamento nas universidades, apoiando a requalificação de espaços e sua alocação, no que se refere à distribuição dos espaços entre as diferentes unidades acadêmicas. Como base conceitual, utiliza-se do conhecimento sobre a qualidade arquitetônica do espaço e sua capacidade de transmitir sensações a seus usuários: a Psicologia Ambiental; o Bioclimatismo; e a Ergonomia. Foi utilizada a base conceitual da Geogestão e a técnica de Arquitetura da Informação para um módulo de apoio à tomada de decisão. A metodologia fundamentou-se na pesquisa bibliográfica; na aplicação de questionários junto aos professores do curso de Arquitetura e Urbanismo da Universidade de Brasília (UnB) para validação e ajuste das características dos espaços; e, ainda, no estudo do atual sistema de informações geoespa- 
ciais da UnB. Como resultado, a pesquisa apresenta o primeiro conjunto de características fruto da pesquisa bibliográfica e a definição das classes a serem agregadas ao sistema de Geogestão da Universidade de Brasília.

\title{
PALAVRAS-CHAVE
}

Geogestão, Espaço arquitetônico, Espaço de aprendizagem, Universidade de Brasília.

\author{
GEO-MANAGEMEN'T APPLIED TO UNIVERSITY SPACE: EASY- \\ LEARNING CHARACTERISTICS OF THE ARCHITECTURAL SPACE
}

\begin{abstract}
The article discusses the architectural space characteristics that help learning in university institutions and their storage system for information management in order to supporting the space development and its allocation regarding the space allocation among different academic units. As a conceptual basis it is used the knowledge about architectural space quality and its ability to transmit sensations to users: environmental psychology; bioclimatism; and ergonomics.

Geo-management and information technic in architecture support decision-making. The methodology was based on literature; questionnaires along with professors of Architecture and Urbanism at the University of Brasilia (UnB) for validation and tuning characteristics of spaces and also study the current system of geospatial information at UnB. As a result, the research presents a set of characteristics found in literature and class definition to be aggregated to Geomanagement system in Brasilia University.
\end{abstract}

\section{KEYWORDS}

Geo-management, Architectural space, Teaching learning, Brasilia University.

\section{INTRODUÇÃO}

A motivação da pesquisa refere-se à reduzida produção de conhecimento sobre o papel do espaço arquitetônico no desempenho das funções do ensino superior e a decorrente carência de informações georreferenciadas para apoio à gestão dos campi universitários no país no que diz respeito à demanda diária de alocação de espaços existentes, expansão ou construção de novos edifícios e requalificação de espaços. A questão colocada foi: como identificar as características do espaço arquitetônico que favoreçam a aprendizagem e seus atributos nos diferentes campos 
disciplinares?

Parte-se da premissa de que o ensino não é aespacial, sendo possível estabelecer relações entre a função deste e a função do espaço, que levem a um maior rendimento da primeira, associando o espaço à dinâmica de inovação e modernização do ensino pelos diferentes tipos de tecnologia. Considera-se, ainda, que a identificação das variáveis dessa relação entre funções pode ser gerenciada para alocar adequados espaços às diferentes demandas de ensino na universidade utilizando sistema de Geogestão.

A articulação arquitetura e educação apresenta múltiplas dimensões, que podem ser tecidas em conjunto, uma vez que ambas são, também isoladamente, pluridimensionais. Para Beltrame e Moura (2009), as questões pertinentes à interação entre espaço físico, atividades pedagógicas e comportamento humano devem ser consideradas prioritárias no processo de elaboração do projeto arquitetônico. O ambiente e os elementos que o compõem formam um conjunto inseparável que interfere diretamente nas pessoas que nele estão inseridas.

Para a abordagem do espaço educativo no ensino superior e a dinâmica de seus processos de forma integrada, o conceito de Sommer (2002) sobre forma e função é utilizado, o que implica entender que os edifícios devem ser construídos, em primeiro lugar, para a função (sua utilidade para o usuário), não para a forma (como alguns arquitetos olham). Suas afirmações são apoiadas em pesquisas sobre a estrutura da sala de aula e como ela afeta o aprendizado.

Referindo-se especificamente a escolas, Prescott (1987) apud Elali (2003) indica a importância de se entender que os efeitos do ambiente educativo são mediados pela política institucional, de modo que modelos demasiadamente limitadores dos comportamentos espontâneos dos estudantes (excessivamente inibidores e/ou modeladores de suas ações) demonstram não suportar seu desenvolvimento. Tal compreensão aponta para a necessidade de as propostas nessa área valorizarem a flexibilidade tanto do ambiente físico quanto do programa, os quais precisariam ser reconhecidos/decodificados pela comunidade escolar como adequados/ aptos ao abrigo dos mais diversos tipos de exigência dos usuários. 


\section{APRESENTAÇÃO DO TEMA}

A identificação das variáveis envolvidas na relação entre função do ensino e função do espaço nos abre um campo de gestão na universidade, que diz respeito à otimização na alocação de espaços adequados às diferentes demandas de ensino.

A utilização dos dados espaciais integrados a metadados para auxiliar na tomada de decisão gerencial tem sido um grande desafio para o geoprocessamento nesta década. Sobre o assunto, têm discorrido vários autores, como Câmara et al. (2001a), Câmara et al. (2001b), Lima-Marques (2007), Moura (2003), Cordovez (2002), Queiroz e Ferreira (2006), Davis Jr. (2000), entre outros.

A preocupação em compartilhar dados geográficos entre instituições públicas, privadas, acadêmicas e a sociedade em geral vem consolidando a estruturação das chamadas Infraestrutura de Dados Espaciais (IDE), ou em inglês Spatial Data Infrastructure (SDI), com o objetivo de evitar a duplicação de esforços entre organizações públicas, melhorar a qualidade e reduzir os custos de coleta e acesso das informações espaciais, aumentar os benefícios que podem advir do uso de dados geográficos disponíveis em atividades de gestão, planejamento, pesquisa e outras para as quais o conhecimento do território seja importante (FGDC, 2007 apud DOMINGUES \& FRANÇOSO, 2008).

Para Cordovez (2002), o geoprocessamento é mais que uma tecnologia, é uma metodologia de gestão, e seus limites na administração estão na imaginação do gestor, e não na própria tecnologia. Conhecer onde os problemas ocorrem e poder visualizá-los espacialmente facilita muito seu entendimento, auxiliando na tomada de decisões. O estágio atual das geotecnologias permite fazer uma análise espacial que combine o mapeamento com informações físicas, demográficas, geográficas, topográficas ou de infraestrutura etc.

A gestão pública pode ser entendida como um conjunto de órgãos, serviços e agentes do Estado, bem como das demais empresas públicas (autarquias), que asseguram a satisfação das necessidades coletivas variadas, tais como segurança, saúde, cultura, educação, lazer e bem-estar 
da população (PORTAL DA CÂMARA MUNICIPAL DE SÃO PAULO, 2012).

Cada vez mais se faz necessário introduzir novas formas de gestão que conduzam a maior motivação, produtividade e obtenção de resultados que possam traduzir-se em benefícios concretos para a sociedade. Assim, a conciliação dos dados e informações, gráficos e alfanuméricos, provenientes de diversas fontes em um banco de dados atualizado constitui uma ferramenta importante no processo de modernização gerencial das administrações públicas.

A Geogestão, por sua vez, constitui-se num sistema baseado em informações georreferenciadas, o qual permite que os processos de tomada de decisão contemplem a disposição física dos atributos das instalações, o uso dos espaços físicos, a alocação dos recursos humanos, a estrutura organizacional dos espaços físicos, a sinalização, dentre outros (SANTA ROSA, 2011).

Segundo o autor, parte-se do princípio de que tudo se encontra definido no espaço e georreferenciado, logo, podem-se utilizar todos os operadores espaciais no conceito de gestão. Todas as funções da gestão podem ser vinculadas a esses operadores. Com isso, podemos definir funções dos processos estimadas pelo tempo e espaço, uma vez que toda a logística fica intrínseca na Geogestão, que é diferente da gestão tradicional.

Na gestão tradicional não há a funcionalidade de tempo, local etc., por exemplo, reforma da sala de aula. O número de alunos e o número de salas de aula. Quanto espaço físico é preciso para comportar $\mathrm{x}$ alunos? Quais são as salas ideais para atender $\mathrm{x}$ alunos? A distribuição das salas precisa seguir a norma existente (laboratórios, salas de aula teórica etc.), pois cada espaço possui dimensões diferenciadas. Com a aplicação da Geogestão, as funções já estão relacionadas. A gestão tradicional trabalha com uma logística estanque, ao passo que, na Geogestão, a logística é dinâmica.

A base da Geogestão é a Geoinformação, que é a união de tão valiosa informação a um atributo geográfico, ou seja, ela tem um endereço, carrega consigo as coordenadas (longitude, altitude e latitude) do local a que se refere, apresentando como fundamento básico a construção de 
representações computacionais do espaço geográfico (GEONET, 2012).

Por sua vez, a Arquitetura da Informação constitui-se numa técnica aplicável a qualquer ambiente informacional, sendo este compreendido como um espaço localizado em um contexto; constituído por conteúdos em fluxo; e que serve a uma comunidade de usuários. A finalidade da Arquitetura da Informação é, portanto, viabilizar o fluxo efetivo de informações por meio do desenho de ambientes de informação (LIMAMARQUES \& MACEDO, 2005).

\subsection{As relações entre espaço arquitetônico e ensino}

Entender a visão dos diferentes campos disciplinares envolvidos no tema é essencial, bem como identificar a recorrência de resultados semelhantes encontrados no que se refere às características do espaço que podem apoiar o aprendizado, objeto da pesquisa bibliográfica empreendida e sintetizada na sequência do artigo.

\subsubsection{Psicologia Ambiental}

Segundo Gifford (2002), a Psicologia Ambiental estuda a transação entre os indivíduos e seus ambientes físicos. Nessas transações, os indivíduos mudam o ambiente, e seu comportamento é mudado pelo ambiente. Psicologia Ambiental inclui a pesquisa e a prática direcionadas para o fazer de construções mais humanas e para melhora do nosso relacionamento com o meio ambiente natural.

Para os psicólogos ambientais, como Campos-de-Carvalho et al. (2011), o ambiente possui um conceito multidimensional. Ele é constituído pelo espaço físico - construído ou natural - e pelas pessoas, acompanhadas das condições sociais, econômicas, políticas, culturais e psicológicas. Devido à relação intrínseca e dinâmica entre pessoa e ambiente, quando é modificado um de seus componentes, os demais se alteram e surge uma nova configuração espacial.

A arquitetura do espaço físico destinado ao aprendizado exerce a sua mais potente influência sobre o comportamento de um modo indireto, promovendo formas particulares de organização social. Em nenhum ou- 
tro local isso é mais evidente do que nos espaços físicos destinados aos propósitos educacionais.

Os efeitos do espaço físico sobre o aprendizado devem ser analisados sob quatro dimensões: o próprio aprendizado, os sentimentos com relação ao aprendizado, o comportamento social relacionado ao aprendizado e os aspectos de saúde e estresse do aprendizado (WEINSTEIN apud GIFFORD, 2002).

\subsubsection{Ergonomia}

A etimologia do vocábulo Ergonomia não especifica bem o objeto dessa disciplina definida como o conjunto de conhecimentos a respeito do desempenho do homem em atividade, a fim de aplicá-los à concepção das tarefas, dos instrumentos, das máquinas e dos sistemas de produção. O objetivo das pesquisas em Ergonomia é "o estudo das trocas regulamentadoras entre o ambiente profissional e o trabalhador" (LAVILLE, 1977, 7).

Segundo este autor, o homem vive e trabalha num ambiente que poderíamos caracterizar por meio de medidas físicas: meio térmico, meio sonoro, meio luminoso e meio vibratório, sendo que ele só pode conservar a integridade de seu organismo quando esses meios não ultrapassam certos limites. A Ergonomia aplica-se, então, em determinar as características ótimas desses meios, de acordo com o tipo de atividades executadas.

\subsubsection{Bioclimatismo}

Para Serra (1987) e Evans \& Schiller (1910), apud Amorim (1998), as características da Arquitetura que influenciaram na economia de energia e na eficiência energética, quando inseridas no projeto arquitetônico de modo a otimizar as relações energéticas com o ambiente natural para alcançar o conforto ambiental, definem a Arquitetura Bioclimática, a qual consiste no desenho dos edifícios tendo em consideração as condições climáticas, utilizando os recursos disponíveis na natureza (sol, vegetação, chuva e vento) para minimizar os impactos ambientais e reduzir o consumo energético, sendo utilizada desde a antiguidade.

Segundo Amorim (1998), variáveis do clima, como a ventilação, e va- 
riáveis da arquitetura, como características projetuais (orientação solar, aberturas, materiais e componentes, cores e sombreamentos) são denominados variáveis bioclimáticas, e definem a Arquitetura Bioclimática. Essas variáveis estão relacionadas à tipologia arquitetônica e, naturalmente, aos estilos característicos de cada região.

Alguns estudos já comprovaram que condições desfavoráveis de conforto ambiental, térmicas, luminosas e acústicas, que resultam em variações climáticas, comprometem o bem-estar e o aproveitamento didático dos alunos que estejam nos ambientes. Os fatores externos podem contribuir ou retardar o processo de ensino-aprendizagem dependendo da natureza de cada elemento. Corroborando esta afirmação, Sommer (1973) destaca as condições ambientais da sala de aula (a acústica, a temperatura, a insolação, a ventilação e a luminosidade) como fatores que podem interferir no desenvolvimento didático. Acrescenta que estas podem refletir-se em fatores tão diversos como a sociabilidade dos usuários, seu desempenho acadêmico e mesmo em sua saúde.

A partir das pesquisas nesses campos disciplinares, foram propostas categorias para agrupar o conjunto de características identificadas nas pesquisas com alguma relevância na relação espaço/aprendizagem. Procurou-se a recorrência com que determinadas características espaciais eram citadas como relevantes no processo de avaliação do desempenho do espaço para função acadêmica, o que está sintetizado nas tabelas 1 e 2. A pesquisa ainda apontou a importância do Projeto Político Pedagógico (PPP) como norteador das atividades e necessário para definição dos atributos espaciais facilitadores da aprendizagem. 
Quadro I - Principais características dos espaços arquitetônicos e relevância no ensino/ aprendizado na visão dos autores

\begin{tabular}{|c|c|c|c|c|c|c|c|c|c|c|c|c|c|c|c|c|c|c|c|c|}
\hline 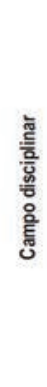 & Caracteristicas & 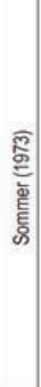 & 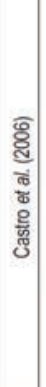 & 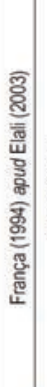 & 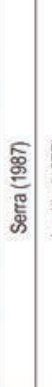 & 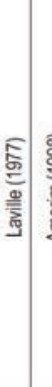 & 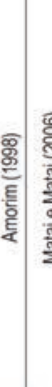 & 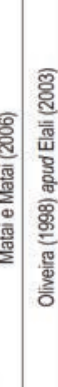 & 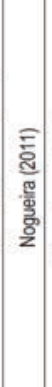 & 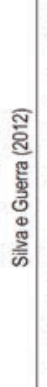 & 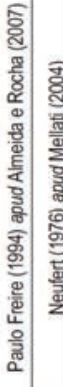 & 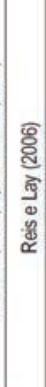 & 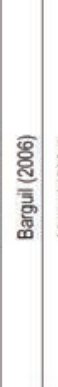 & 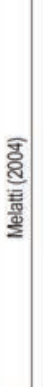 & 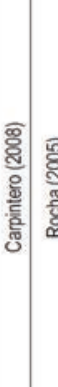 & 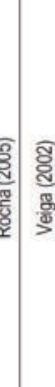 & 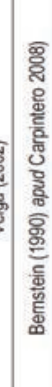 & 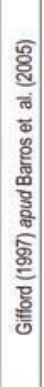 & 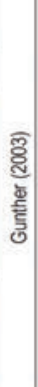 & 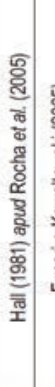 \\
\hline \multirow{7}{*}{ 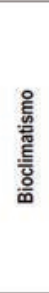 } & Iluminaçăo & & & & & & & & & & & & & & & & & & & \\
\hline & Ventilaçāo & & & & & & & & & & & & & & & & & & & \\
\hline & Acuistica & & & & & & & & & & & & & & & & & & & \\
\hline & Conforto térmico & & & & & & & & & & & & & & & & & & & \\
\hline & Sonorizaçăo & & & & & & & & & & & & & & & & & & & \\
\hline & Climatização & & & & & & & & & & & & & & & & & & & \\
\hline & Cores & & & & & & & & & & & & & & & & & & & \\
\hline \multirow{8}{*}{ 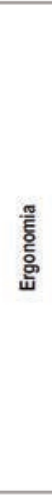 } & Dimensão & & & & & & & & & & & & & & & & & & & \\
\hline & $\begin{array}{c}\text { Flexibilidadel } \\
\text { espaços } \\
\text { adaptabilidade }\end{array}$ & & & & & & & & & & & & & & & & & & & \\
\hline & $\begin{array}{l}\text { Multifuncionalidade } \\
\text { na Infraestrutura }\end{array}$ & & & & & & & & & & & & & & & & & & & \\
\hline & $\begin{array}{c}\text { Tecnologia } \\
\text { equipamentos }\end{array}$ & & & & & & & & & & & & & & & & & & & \\
\hline & Estêtica & & & & & & & & & & & & & & & & & & & \\
\hline & Acessibilidade & & & & & & & & & & & & & & & & & & & \\
\hline & $\begin{array}{l}\text { Mobiliário } \\
\text { e/equipamentos }\end{array}$ & & & & & & & & & & & & & & & & & & & \\
\hline & Comunicação visual & & & & & & & & & & & & & & & & & & & \\
\hline \multirow{4}{*}{ 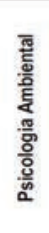 } & $\begin{array}{c}\text { Espaço pessoal, } \\
\text { privacidade, } \\
\text { territorialidade }\end{array}$ & & & & & & & & & & & & & & & & & & & \\
\hline & Mobilidade & & & & & & & & & & & & & & & & & & & \\
\hline & Amplidão, nichos. & & & & & & & & & & & & & & & & & & & \\
\hline & $\begin{array}{l}\text { Distanclas } \\
\text { interpessoais }\end{array}$ & & & & & & & & & & & & & & & & & & & \\
\hline
\end{tabular}

Fonte: Elaboração própria 


\section{Quadro II - Características (atributos) dos espaços físicos necessárias ao ensino/aprendizagem}

\begin{tabular}{|c|c|c|c|}
\hline $\begin{array}{c}\text { Campo } \\
\text { disciplinar }\end{array}$ & Conceito & Atributo & Descritor \\
\hline \multirow{8}{*}{ 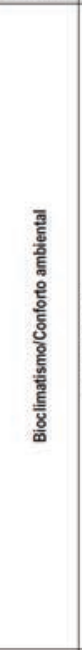 } & \multirow{8}{*}{$\begin{array}{l}\text { Os fatores externos } \\
\text { podem contribuir ou } \\
\text { retardar o processo de } \\
\text { ensino-aprendizagem } \\
\text { dependendo da } \\
\text { natureza de cada } \\
\text { elemento. }\end{array}$} & lluminaçăo & $\begin{array}{l}\text { Fenomeno fisico resultante da exposiçăo de uma fonte de luz } \\
\text { num ambiente que pode absomver ou refletir a luz, tomando-se } \\
\text { visivel. }\end{array}$ \\
\hline & & Ventilação & $\begin{array}{l}\text { Variavel bioclimatica que proporciona conforto ambiental das } \\
\text { edificaçoses a partir da temperatura. }\end{array}$ \\
\hline & & Conforto visual & $\begin{array}{l}\text { Grau de satisfaçăo visual produzido pelo ambiente liuminado. } \\
\text { Propbe reduzir ofuscamentos visuais, equilibrar a iluminancia e } \\
\text { ampliar a reproduçăo de cores, permitindo que o olho tenha } \\
\text { uma perfeita dimensăo dos espaços do ambiente, volume das } \\
\text { formas, texturas dos materiais e fidelidade de cores. }\end{array}$ \\
\hline & & Acistica & $\begin{array}{l}\text { Ramo da Fisica que estuda o som. O som é um fenómeno } \\
\text { ondulatório causado pelos mais diversos objetos, e se propaga } \\
\text { atraves dos diferentes estados fisicos da matéria. }\end{array}$ \\
\hline & & Conforto termico & 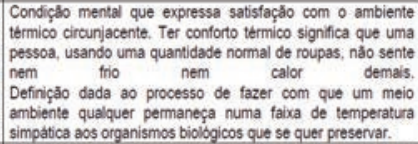 \\
\hline & & Sonorizaçato & $\begin{array}{l}\text { Reforço de som para que um evento dependente da produçalo } \\
\text { de som possa ser assistido por uma massa de espectadores } \\
\text { que, pelo tamanho ou quantidade de pessoas, nalo conseguiria } \\
\text { ouvir o evento. }\end{array}$ \\
\hline & & Climabizaçăo & $\begin{array}{l}\text { Definiçào dada ao processo de fazer com que um meio } \\
\text { ambiente qualquer permaneça numa faixa de temperatura } \\
\text { simpática aos organismos biologicos que se quer preservar. }\end{array}$ \\
\hline & & Cores & $\begin{array}{l}\text { Alem de funcionar como instrumento de melhora da condiçăo } \\
\text { visual (pela reflexâ), a cor, como ja foi mencionado, tem } \\
\text { funçbes terapeuticas. }\end{array}$ \\
\hline \multirow{5}{*}{ 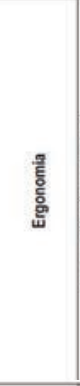 } & \multirow{5}{*}{$\begin{array}{l}\text { Conjunto de } \\
\text { conhecimentos a } \\
\text { respeito do } \\
\text { desempenho do } \\
\text { homem em atvidade, } \\
\text { a fim de aplica-los a } \\
\text { concepçaso das tarefas } \\
\text { dos instrumentos, das } \\
\text { maquinas e dos } \\
\text { sistemas de produçalo. }\end{array}$} & Dimensao & $\begin{array}{l}\text { Porcentagem de área destinada as funçoses do ensino superior, } \\
\text { conforme definido em Norma técnica - ABNT. }\end{array}$ \\
\hline & & $\begin{array}{l}\text { Flexiblidade dos } \\
\text { espaços, adaptabilidade }\end{array}$ & $\begin{array}{l}\text { E necessario que os projetos de escolas pensem edificaçbes } \\
\text { que possam ser modificadas e adaptadas ao longo dos anos. }\end{array}$ \\
\hline & & $\begin{array}{l}\text { Multifuncionalidade na } \\
\text { Infraestrutura }\end{array}$ & $\begin{array}{l}\text { A disposiça da intraestrutura fisica da escola concorre para o } \\
\text { sucesso do trabalho pedagogico dos meios fisicos nos recintos } \\
\text { escolares e das areas abertas. }\end{array}$ \\
\hline & & Tecnologia/equipamentos & $\begin{array}{l}\text { Com o avanço tecnológico existente em nossa sociedade, o } \\
\text { ambiente escolar sofre modificaç̧es, as quais influenciam o } \\
\text { processo ensino-aprendizagem. }\end{array}$ \\
\hline & & Estetica & $\begin{array}{l}\text { A categoria estética refere-se nß̊ exclusivamente aos } \\
\text { elementos arquitetónicos de uma edificaçalo ou de um espaço } \\
\text { urbano, mas à relaçalo estetica destes com as edificaçbes e } \\
\text { espaços abertos adjacentes e nas proximidades. }\end{array}$ \\
\hline \multirow{7}{*}{ 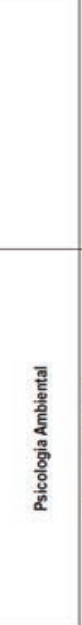 } & \multirow{7}{*}{$\begin{array}{l}\text { Individuos por meio } \\
\text { de suas aç̧es } \\
\text { modifcam o ambiente } \\
\text { e ambientes por meio } \\
\text { de suas configuraçbes } \\
\text { influenciam o } \\
\text { comportamento } \\
\text { humano. }\end{array}$} & Acessibilidade & $\begin{array}{l}\text { Facilidade de acesso para todas as pessoas, normais ou com } \\
\text { necessidades especiais (portadores de deficienclas, } \\
\text { acidentados, gestantes, idosos e crianças). }\end{array}$ \\
\hline & & $\begin{array}{l}\text { Mobiliarioe } \\
\text { equipamentos }\end{array}$ & $\begin{array}{l}\text { O mobiáario deve ser flexivel, adaptavel por meio de rodizios; t } \\
\text { os equipamentos de tecnologia sem fio (wireless) permitem } \\
\text { diversos amanjos de acordo com as atividades a serem } \\
\text { desenvolvidas. contribuindo para a adaptabilidade do } \\
\text { ambiente. }\end{array}$ \\
\hline & & Comunicaçăo visual & $\begin{array}{l}\text { Conjunto de conhecimentos e técnicas que buscam maior } \\
\text { eficacia na transmissăo visual de mensagens, verbais ou năo } \\
\text { verbais. }\end{array}$ \\
\hline & & $\begin{array}{l}\text { Espaço pessoal, } \\
\text { territorialidade, } \\
\text { privacidade }\end{array}$ & $\begin{array}{l}\text { Espaço pessoal - espaço invisivel que circunda o individuo e } \\
\text { funciona como um regulador das relaç̧es interpessoais. } \\
\text { Ternitorialidade - baseado em controle percebido, tentado ou } \\
\text { real. } \\
\text { Privacidade - controle seletivo do acesso a si mesmo ou a seu } \\
\text { "grupo", igualmente supje uma outra pessoa, cujo acesso } \\
\text { precisa ser controlado. }\end{array}$ \\
\hline & & Mobilidade, & $\begin{array}{l}\text { O grau de mobilidade afeta o acesso a duas classes de } \\
\text { elementos: (a) bens materiais e ideias importantes subjetiva e } \\
\text { objetivamente; } \mathrm{e} \text { (b) affordances do ambiente. }\end{array}$ \\
\hline & & Amplidåo, nichos. & $\begin{array}{l}\text { Amplidáo possibilita a adaptablidade do ambiente, permitindo } \\
\text { o ajuste das distäncias interpessoais. } \\
\text { Nichos săo configurados por mobiliário eiou estruturas fisicas } \\
\text { (como paredes e materiás de acabamento) e destacam o } \\
\text { espaço pessoal. }\end{array}$ \\
\hline & & Distâncias interpessoais & $\begin{array}{l}\text { Referem-se às distàncias adequadas para contato ou náo } \\
\text { contato, podendo gerar reaçbes comportamentais positivas ou } \\
\text { negativas. }\end{array}$ \\
\hline
\end{tabular}

Fonte: Elaboração própria 


\section{METODOLOGIA UTILIZADA}

Como metodologia, combinam-se vários métodos, a começar pela pesquisa bibliográfica sobre as características espaciais facilitadoras do aprendizado nos campos descritos na base conceitual (quadro 2), seguida de sua validação por meio de estudo da Faculdade de Arquitetura da Universidade de Brasília no que se refere às diretrizes pedagógicas do curso, de onde emanam os campos disciplinares que devem ser ministrados para a formação do arquiteto e correspondem aos usos, o que remete às características próprias dos espaços em apoio à atividade de ensino.

O método utilizado será a aplicação de questionários junto ao quadro de professores da FAU-UnB, responsáveis pelas diferentes disciplinas em que está estruturado o curso. A tabulação da pesquisa permitirá a confirmação e ajuste das características do espaço arquitetônico que possibilitará a formatação de um módulo do sistema de Geogestão, com usos possíveis tanto na alocação de espaços quanto no fornecimento de insumos à projetação e requalificação de espaços na universidade.

\section{Apresentação dos dados - Módulo ACAdêmico no Sistema de GEOINFORMAÇÃO DA UNIVERSIDADE DE BRASíLIA}

No campo da gestão da universidade pública no Brasil, tem-se colocado como um imperativo melhorar a qualidade dos serviços prestados, bem como a capacidade gerencial, e, para tanto, faz-se necessário um novo modelo de gestão universitária, com maior capacidade de ação, com mecanismos de controle social e acesso à informação (MARQUES, 2000).

A Geogestão aplicada à Universidade levará a um modelo de controle, gerenciamento, desempenho e transparência, focado em resultados orientados para a tomada de decisão e satisfação do cidadão. Com isso, informações produzidas nas Instituições Federais de Ensino Superior (IFES), mas de interesse nacional, poderão ser acessadas pelo Governo Federal e Regional devido ao estabelecimento de padrões de intercâmbio de informações.

A Universidade de Brasília (UnB) possui os campi nas cidades de 
Planaltina, Gama e Ceilândia, no Distrito Federal, e o maior deles é o Campus Universitário Darcy Ribeiro, localizado no Plano Piloto de Brasília, que abriga mais de 120 edificações, praças, vias e estacionamentos distribuídos por uma área de 550 hectares, onde circulam cerca de 35.000 pessoas e 25.000 veículos diariamente, e possui um total de 550.000 metros quadrados de área construída. Além dos campi há as unidades dispersas, como a Fazenda Água Limpa, o Hospital Universitário de Brasília, o Edifício OK, o Edifício Anápolis, entre outros.

A Universidade de Brasília vem enfrentando os desafios referentes ao processo de avaliação institucional, da qualidade de sua gestão e do ensino, pesquisa e extensão, e, dentro desta ótica, faz parte a criação de sistemas de informações cadastrais georreferenciadas e integradas, que permitam a devida atualização e controle sobre os dados cadastrais dos campi e, consequentemente, da gestão universitária.

\subsection{O sistema existente e suas possibilidades}

A Universidade de Brasília, até 2006, dispôs de um sistema de dados alfanuméricos - Sistema de Registro e Concessão de Uso (SIRC), que articulava seu espaço físico e a estrutura organizacional, capaz de registrar e armazenar informações de todos os Centros de Custo e Órgãos vinculados. Os espaços físicos são identificados por características como: localização da edificação no campus; o tipo de uso que o espaço tem; endereço; funcionamento que ocorre no espaço etc.

A organização e a praticidade com que as informações são extraídas dos relatórios do sistema são fatores muito positivos, e fazem com que a comunidade seja atendida em vários tipos de demanda, em sua maioria de caráter administrativo. A seguir, são apresentadas algumas telas possíveis emitidas pelo sistema.

Na primeira parte temos um bloco de parâmetros referentes ao espaço físico do que procuramos. 


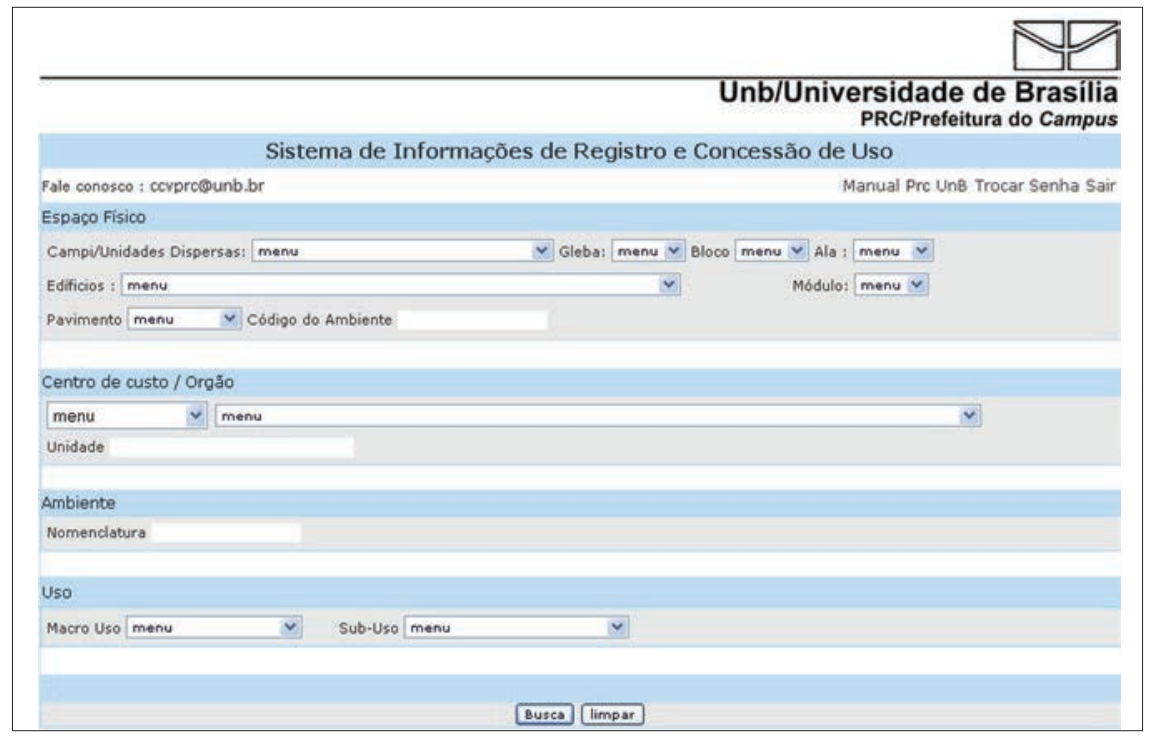

Figura 1 - Tela inicial do SIRC

Fonte: PRC/UnB (2006)

Observe a tela abaixo e veja o que temos nesse bloco.

Sistema de Informações de Registro e Concessão de Uso
$\begin{aligned} & \text { Fale conosco : cevproథunb.br } \\ & \text { Espaço Fisico } \\ & \text { Campivinidades Dispersas: menu } \\ & \text { Edificios : menu } \\ & \text { Pavimento menu } \vee \text { Código do Ambiente }\end{aligned}$

Figura 2 - Bloco de parâmetros referentes ao espaço físico Fonte: PRC/UnB (2006)

O parâmetro Campi/Unidades Dispersas é o primeiro que é mostrado, e por ele começamos a identificar o endereço de um espaço físico. Ao selecionar esse campo, serão mostrados todos os campi e unidades dispersas que estão cadastrados no sistema. Selecione um campo e prossiga com a consulta. 


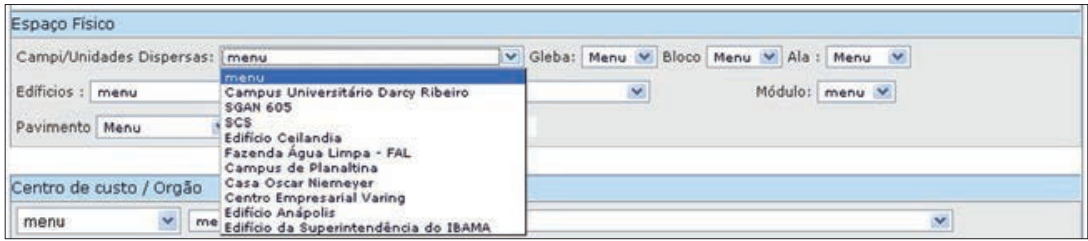

Figura 3 - Menu com os Campi e as Unidades Dispersas Fonte: PRC/UnB (2006)

O próximo campo localizado à direita é a Gleba. Esse campo somente será visualizado pelo usuário caso nenhum outro parâmetro tiver sido selecionado ou o campus escolhido tiver sido o Campus Universitário Darcy Ribeiro. Selecione uma das opções e prossiga com a consulta.

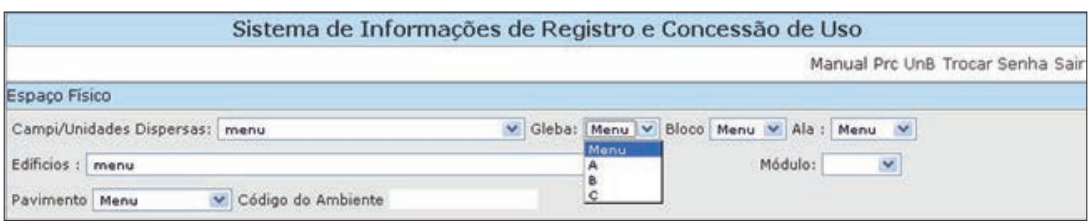

Figura 4 - Menu Gleba

Fonte: PRC/UnB (2006)

O parâmetro seguinte a ser escolhido é o Bloco. Na tela seguinte, selecione uma das opções e prossiga com a consulta.

\begin{tabular}{|c|c|c|}
\hline \multicolumn{3}{|c|}{ Sistema de Informações de Registro e Concessão de Uso } \\
\hline & & Manual Prc UnB Trocar Senha Sair \\
\hline \multicolumn{3}{|l|}{ Espaço Fisico } \\
\hline Campi/Unidades Dispersas: menu & $\sim$ Gleba: Menu $\sim$ aloco Menu V & Ala : Menu $v$ \\
\hline Edificios: menu & $\sim$ & ulo: : \\
\hline ح Codigo do Ambiente & c & \\
\hline
\end{tabular}

Figura 5 - Menu Bloco

Fonte: PRC/UnB (2006)

O próximo campo a ser escolhido é a Ala. Esse campo somente será visualizado pelo usuário caso nenhum outro parâmetro tiver sido escolhido ou o prédio escolhido tiver sido o Instituto Central de Ciências ou 
a Faculdade de Tecnologia. Selecione uma das opções e prossiga com a consulta.

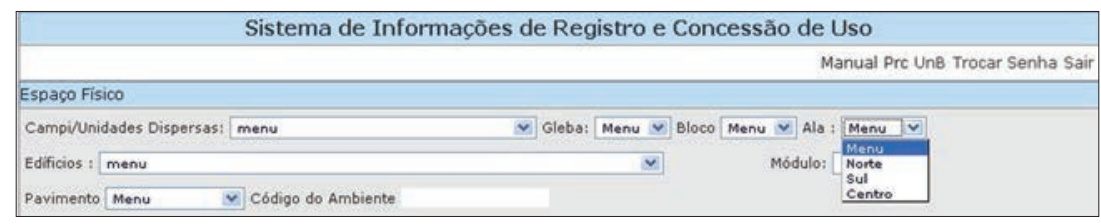

Figura 6 - Menu Ala

Fonte: PRC/UnB (2006)

O campo seguinte é o Edifício. Nele podemos escolher os edifícios referentes somente ao campus selecionado. Se o usuário não escolher nenhum outro parâmetro, o campo Edifícios mostrará todos os edifícios de todos os campi cadastrados. Selecione um campo e prossiga com a consulta.

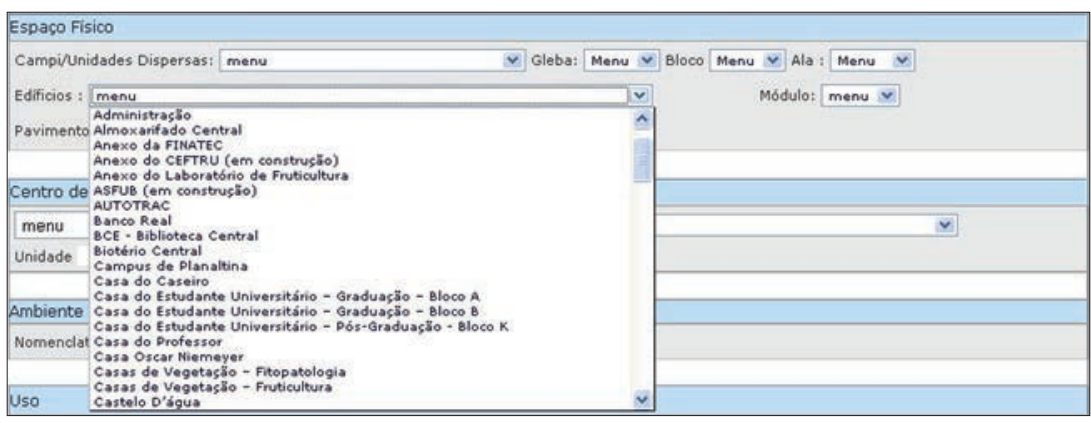

Figura 7 - Menu Edifícios

Fonte: PRC/UnB (2006)

O próximo parâmetro a ser analisado é o Módulo. Nesse campo, aparecem para o usuário os números 1 ao 26, lembrando que esse campo somente será visualizado caso nenhum outro parâmetro tiver sido selecionado, o prédio escolhido tiver sido o Instituto Central de Ciências ou o campus escolhido tiver sido o Campus Universitário Darcy Ribeiro. Selecione um campo e prossiga com a consulta. 


\begin{tabular}{|c|c|c|c|c|}
\hline \multicolumn{5}{|l|}{ Espaço Fisico } \\
\hline Campi/Unidades Dispersas: menu & $\sim$ Gleba: Menu v & Bloco Menu $\sim$ Ala : & Menu $v$ & \\
\hline Edificios: menu & a & Modulo: & menu 2 & \\
\hline Pavimento Menu $\quad$ Código do Ambiente & & & & \\
\hline & & & 24 & \\
\hline Centro de custo / Orgăo & & & 10 & \\
\hline v) menu & & & 12 & $\checkmark$ \\
\hline Unidade & & & 17 & \\
\hline
\end{tabular}

Figura 8 - Menu Módulo

Fonte: PRC/UnB (2006)

O campo seguinte é o Pavimento, e nele podemos escolher em que pavimento do edifício queremos encontrar o espaço físico. Se nenhum parâmetro tiver sido escolhido, essa caixa de seleção, então, mostrará todos os pavimentos que estão cadastrados. Selecione um campo e prossiga com a consulta.

O próximo parâmetro é o Código do Ambiente. Esse campo é aberto para digitação, portanto o usuário deve somente utilizá-lo caso ele conheça o código correto para que a busca realizada possa trazer algum registro válido. Nesse campo, colocamos o código adotado para cada ambiente. Selecione um campo e prossiga com a consulta.

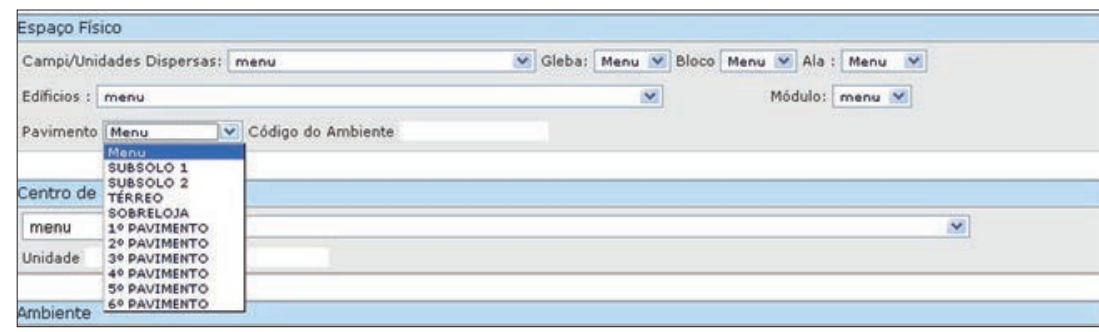

Figura 9 - Menu Pavimento Fonte: PRC/UnB (2006)

Na segunda parte, temos um bloco de parâmetros referentes aos Centros de Custo e Órgãos. Observe a tela abaixo e veja o que temos nesse bloco. 


\begin{tabular}{|l|}
\hline Centro de custo / Org\$0 \\
\hline menu \\
Unidade \\
\hline \\
\hline Ambiente \\
\hline Nomenclatura \\
\hline
\end{tabular}

Figura 10 - Centros de Custo e Órgãos

Fonte: PRC/UnB (2006)

No primeiro menu desse bloco de informações, temos os Centros de Custo divididos por categoria. A seleção desse menu faz uma filtragem no menu ao lado, onde são mostrados somente os Centros de Custo/Órgãos relacionados com a categoria selecionada no primeiro menu. Selecione um campo e prossiga com a consulta.

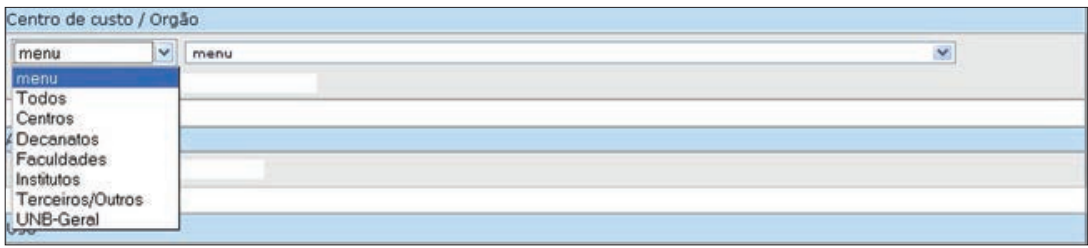

Figura 11 - Menu Centros de Custo e Órgãos Fonte: PRC/UnB

O segundo menu mostra o resultado da escolha feita no menu de categorias de Centros de Custo e Órgãos. Caso o primeiro menu não seja escolhido, serão mostrados todos os centros de custo cadastrados no sistema. Para efeitos práticos, a escolha de um centro de custo selecionando primeiro a categoria e depois o centro de custo referente a ele, ou escolher o centro de custo diretamente sem fazer a escolha da categoria, não trará qualquer registro diferente que ambos tenham. Selecione um campo e prossiga com a consulta.

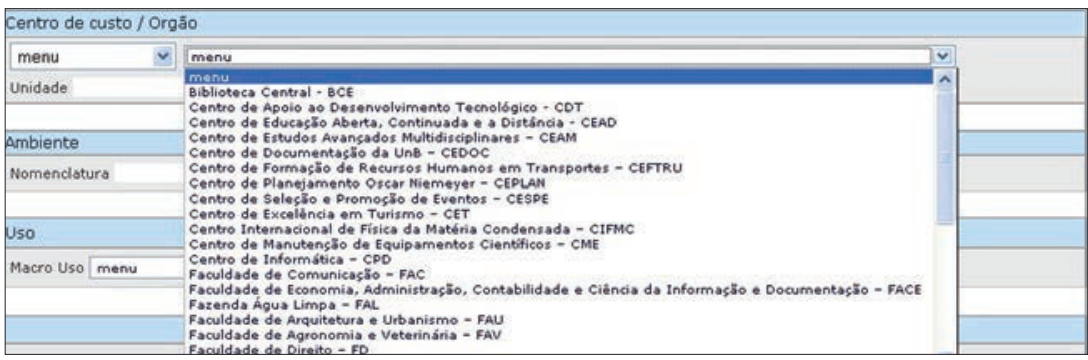

Figura 12 - Menu de categorias de Centros de Custo e Órgãos Fonte: PRC/UnB (2006). 


\section{DISCUSSÃO DOS RESULTADOS}

O Projeto Geogestão dos Espaços Físicos da Universidade de Brasília está sendo implementado pela Faculdade de Ciência da Informação, mais especificamente no Centro de Pesquisa em Arquitetura da Informação/ CPAI, desde 2010. Sua base de dados está contemplada em planilhas em Excel (dados alfanuméricos), e apresenta dificuldades na extração das informações dos espaços físicos, edificações e malha urbana dos campi da UnB, que se encontram em plantas cadastrais extensão DWG (dados geográficos).

A partir da transformação dos dados geográficos em DWG para arquivos shapefile estes serão inseridos no banco de dados espacial Postgree/ PostGIS, e, após a realização do relacionamento das novas tabelas do módulo acadêmico e as existentes, será reestruturada a modelagem dos dados, contemplando as novas classes.

Utilizando o software Postgre/PostGIS em linguagem SQL (Structure Query Language), por meio da ferramenta Query Builder do PgAdmin serão efetuadas consultas por junção espacial e análises diversas no que se refere aos objetos espaciais (dado geográfico que possui uma localização geográfica, expressas como coordenadas em um mapa) e seus atributos descritivos.

A utilização dos softwares Geoserver, Tomcat e GeoNetwork para disponibilização de projetos de localização de camadas de informação existentes no Banco de Dados na Web possibilitará a geração de mapas interativos cadastrais e metadados, dados sobre os dados, que descrevem conteúdo, condição, histórico, localização e outras características do dado, no ambiente Web, referentes às consultas realizadas no Banco de Dados no PostgreSQL/PostGIS.

\subsection{Aprimoramentos para um sistema de Geogestão}

A implantação da base do sistema de Geogestão da Universidade de Brasília constituir-se-á na base para a implementação do módulo acadêmico que contemple a pesquisa das características facilitadoras do aprendizado, pois ter-se-á um ambiente com o controle e informações 
confiáveis de dados espaciais para referenciar as informações.

Utilizando da arquitetura da informação, iniciou-se o desenho do modelo relacional com várias classes que contêm várias tabelas relacionadas, sendo que o módulo acadêmico vem adicionar/integrar novos dados ao Projeto Geogestão para conhecer as necessidades de cada campo disciplinar em tempo real, possibilitando tanto uma melhor alocação de espaços quanto subsidiando a requalificação e projetação de novos espaços.

$\mathrm{Na}$ estrutura da modelagem dos dados alfanuméricos do cadastro de espaço físico serão acrescentadas às novas classes para implementação do módulo acadêmico as seguintes:

Quadro III - Classes e atributos do módulo acadêmico

\begin{tabular}{|c|c|}
\hline CLASSES & ATRIBUTOS \\
\hline Cursos & $\begin{array}{c}\text { Nome } \\
\text { Órgão Interno } \\
\text { Órgão Externo } \\
\text { Sigla do Curso } \\
\text { Departamento } \\
\text { Ambiente } \\
\text { Período } \\
\text { Código }\end{array}$ \\
\hline Disciplinas & $\begin{array}{c}\text { Nome } \\
\text { Código } \\
\text { Órgão Interno } \\
\text { Órgão Externo } \\
\text { Departamento } \\
\text { Ementa } \\
\text { Tipo - Optativa, Obrigatória, Módulo Livre, Estágio Supervisionado } \\
\text { Número de Créditos } \\
\text { Pré-Requisito } \\
\text { Ambiente Horário } \\
\text { Dia da Semana }\end{array}$ \\
\hline Classe Pessoa & $\begin{array}{c}\text { Nome } \\
\text { Órgão Interno } \\
\text { Órgão Externo } \\
\text { Departamento } \\
\text { Titulação - Graduação, Mestrado, Doutorado, Pós- } \\
\text { Doutorado Tipo - Substituto, Visitante etc. }\end{array}$ \\
\hline Função & Nome \\
\hline $\begin{array}{l}\text { Estrutura do } \\
\text { currículo }\end{array}$ & $\begin{array}{l}\text { Disciplinas obrigatórias e/ou optativas, estágios, tra- } \\
\text { balho de conclusão do curso, período }\end{array}$ \\
\hline Nível de ensino & Graduação, pós-graduação, pesquisa e extensão \\
\hline $\begin{array}{l}\text { Características } \\
\text { do espaço }\end{array}$ & $\begin{array}{c}\text { Conforto ambiental - visual, térmico, acústico, luminoso } \\
\text { Psicologia Ambiental - espaço pessoal, mo- } \\
\text { bilidade, distância interpessoal etc. } \\
\text { Ergonomia - mobiliário, comunicação visual }\end{array}$ \\
\hline
\end{tabular}

Fonte: Elaboração própria 


\section{CONCLUSÃo}

A validação e o ajuste do quadro de características facilitadoras da aprendizagem estão sendo testados para o caso da Faculdade de Arquitetura e Urbanismo, com questionários aplicados a todos os professores responsáveis por disciplinas da grade curricular específica e posterior definição do indicador de cada característica para inserção no sistema.

Esse procedimento deverá ser adotado nos demais cursos, de modo a se ter características gerais e específicas por campo disciplinar, capazes de alimentar o sistema de Geogestão da Universidade de Brasília.

\section{BIBLIOGRAFIA}

ALMEIDA, Claudia Maria de et al. (2007) - Geoinformação em urbanismo: Cidade Real X Cidade Virtual. Oficina de Textos, São Paulo, 366 p.

AMORIM, Claudia Naves David (1998) - Desempenho Térmico de Edificações e Simulação Computacional no Contexto da Arquitetura Bioclimática: estudo de caso da Região de Brasília. Dissertação de Mestrado em Arquitetura apresentada à Universidade de Brasília.

BARGUIL, Paulo Meireles (2006) - O Homem e a conquista dos espaços. O que os alunos e os professores fazem, sentem e aprendem na escola. UFCE, Fortaleza, 427 p.

BARROS, Raquel R. M. Paula et al. (2005) - "Conforto e Psicologia Ambiental: A Questão do espaço pessoal no Projeto Arquitetônico”. ENCAC-ELACAC 2005, Maceió, Alagoas, Brasil - 5 a 7 de outubro de 2005.

BELTRAME, Maria Bontorin \& MOURA, Graziella Ribeiro Soares (2009) - "Edificações escolares: Infraestrutura Necessária ao Processo de Ensino e Aprendizagem Escolar. Projeto Saber". Revista Travessias, Vol. 3, № 2. Disponível online no endereço url: http://www.unioeste.br/prppg/mestrados/letras/revistas/ travessias/ed_006/EDUCA\%C7AO/PDF/EDIFICA\%C7\%D5ES\%20ESCOLARES. pdf (acedido em janeiro, 2013).

CÂMARA, Gilberto et al. (2001a) - Introdução à Ciência da Geoinformação: Conceitos Básicos em Ciência da Geoinformação. INPE (INPE-8563-PRE/ 307. São Paulo/SP), São José dos Campos.

CÂMARA, Gilberto et al. (2001b) - Fundamentos Epistemológicos da Ciência da GeoInformação. Disponível online no endereço url: www.dpi.inpe.br/ gilberto/livro/introd/cap5-epistemologia.pdf. (acedido em março, 2009). 
CAMPOS-DE-CARVALHO, Mara Ignez et al. (2011) - "Ambiente", in CAVALCANTE, Sylvia \& ELALI, Gleice (orgs.): Temas básicos em Psicologia Ambiental. Vozes, Petrópolis, 28-43.

CARPINTERO, Antonio Carlos \& ALMEIDA, Jaime Gonçalves (2008) - Teorias do espaço educativo. Módulo 10. Universidade de Brasília, 106 p.

CASTRO, Iara Souza et al. (2006) - Cognição e Percepção Visual: a Influência da Iluminação artificial sobre uma Atividade de Trabalho realizada em um ambiente informatizado confinado. $14^{\circ}$ Congresso Brasileiro de Ergonomia, Curitiba/PR. Disponível online no endereço url: http://www.iar.unicamp.br/ lab/luz/ld/Linguagem\%20Visual/cognicao_e_percepcao_visual.pdf (acedido em dezembro, 2013).

CORDOVEZ, Juan Carlos Gortaire (2002) - "Geoprocessamento como Ferramenta de Gestão Urbana”, in Anais do I Simpósio Regional de Geoprocessamento e Sensoriamento Remoto. Aracaju/SE, 17 e 18 de outubro de 2002. Disponível online no endereço url: http://www.cpatc.embrapa.br/labgeo/srgsr1/pdfs/ pa_pu_01.PDF (acedido em janeiro, 2010).

DAVIS JÚNIOR, Clodoveu Augusto (2000) - Múltiplas Representações em Sistemas de informação Geográficos. Tese de Doutorado em Ciências da Computação apresentada à Universidade Federal de Minas Gerais.

DOMINGUES, Cristiane Vaz V. \& FRANÇOSO, Maria Tereza (2008) - "Aplicação de Geoprocessamento no Processo de Modernização da Gestão Municipal”. Revista Brasileira de Cartografia, ISSN 1808-0936, № 60/01. Disponível online no endereço url: http://www.rbc.lsie.unb.br/index.php/rbc/article/ viewFile/56/56. (Acedido em janeiro, 2012).

ELALI, Gleice Azambuja (2003) - "O ambiente da escola: uma discussão sobre a relação escola-natureza em educação infantil”. Estudos de Psicologia, Vol. 8, № 2, 309-319. Disponível online no endereço url: http//www.scielo.br/ pdf/epsic/v8n2/1904 (acedido em 2 março, 2013).

FUNARI, Teresa B. S \& KOWALTOWSKI, Doris C. C. K. (2005) - "Arquitetura Escolar e Avaliação Pós-ocupação”. ENCAC-ELACAC, Maceió, Alagoas, Brasil. Disponível online no endereço url: pesqdoris.e-social.com.br/ publicacoes/?task=getfile $\&$ file $=$ pub (acedido em novembro, 2013).

GEONET (2012). Disponível online no endereço url: <exhttp://geonet.ctbctelecom. com.br/glossario.cfm (acedido em setembro, 2012).

GIFFORD, Robert (2002) - Environmental Psychology, Principles and Practice. 3rd, Ed. Optimal Books, Canadá.

GUNTHER, Hartmut (2003) - "Mobilidade e affordance1 como cerne dos Estudos Pessoa-Ambiente”. Estudos de Psicologia, Vol. 8, № 2, 27.

LAVILLE, Antoine (1977) - Ergonomia. EPU, EDUSP, São Paulo, 99 p. 
LIMA-MARQUES, Mamede \& MACEDO, Flavia Lacerda Oliveira de (2005) "Arquitetura da Informação: base para a Gestão do Conhecimento", in TARAPANOFF, K. (org.): Gestão da Informação e do Conhecimento em Organizações. Glonal Editora, 1ạ ed., São Paulo, 177-192.

LIMA-MARQUES, Mamede (2007) - Arquitetura da Informação. Disponível online na url: http://aprender.unb.br/course/view.php?id=1014 (acedido em junho, 2009).

MARQUES, Maria da Conceição da Costa (2000) - Alguns Aspectos da Gestão Pública na Administração Central em Portugal. Universidade Aberta Comunicación presentada en el I Encuentro Iberoamericano de Contabilidad de Gestión. Valencia - Noviembre. Disponível online no endereço url: http://www. observatorio-iberoamericano.org/paises/spain/art\%C3\%ADculos\%20diversos $\% 20$ sobre $\% 20$ contabilidad $\% 20 \mathrm{de} \% 20$ gesti $\%$ C3\%B3n/I\%20Encuentro \%20Iberoamericano\%20Cont.\%20Gesti\%C3\%B3n/Proyecciones\% 20Sectoriales/ MariaCCosta.pdf (acedido em agosto, 2012).

MATAI, Patrícia Helena Lara dos Santos \& MATAI, Shigueharu (2006) - "Ensino Cooperativo: Espaço Físico" in Anais do XXXIV Congresso Brasileiro de Ensino de Engenharia Universidade de Passo Fundo, 1314-1328. Disponível online no endereço da url: http://www.dee.ufma.br/ fsouza/anais/ arquivos/1113769.pdf (acedido em 25 maio, 2010).

MELATTI, Sheila Pércia do Prado Cardoso (2004) - A arquitetura escolar e a prática pedagógica. Joinville, 2004. Disponível online na url: http://www.tede.udesc. br/tde_busca/arquivo.php?codArquivo=277 (acedido em outubro, 2013).

MOURA, Ana clara Mourão (2003) - Geoprocessamento na Gestão e Planejamento Urbano. Ed. da Autora, Belo Horizonte, 294 p.

NOGUEIRA, Esther (2011) - A importância do espaço como fator de desenvolvimento, Aprendizagem e Bem Estar das crianças e professoras e como parte integrante da ação pedagógica - $3^{\mathrm{a}}$ Formação PAIC. Secretaria Municipal de educação. Educação Infantil de Juazeiro do Norte. Disponível online na url: http://www.google.com.br/url?sa=t\&rct=j\&q= $\&$ esrc $=$ s $\&$ frm $=1 \&$ source $=$ web $\& \mathrm{~cd}=1 \&$ ved=0CDAQFjAA $\&$ url $=$ http $\% 3 \mathrm{~A} \% 2 \mathrm{~F} \%$ 2Fxa.yimg.com\%2Fkq\%2Fgroups\%2F27271184\%2F897245085\%2Fname $\%$ 2FUNKNOWN_PARAMETER_VALUE\&ei=LC8qUb3sN4eW8gTfzoGgBg\&usg =AFQjCNFESyFqbSZ5kvBUYIYbCsZw08Ze9A\&sig2=g6fVyvNfdtRaB32FQ ytZtg\&bvm=bv.42768644,d.eWU (acedido em janeiro, 2013).

PORTAL DA CÂMARA MUNICIPAL DE SÃO PAULO (2013). Disponível online no endereço url: http://www.camara.sp.gov.br/index.php?option=com content\&view $=$ article $\& i d=350 \& I t e m i d=135$ (acedido em setembro, 2013).

QUEIROZ, Gilberto Ribeiro \& FERREIRA, Karine Reis (2006) - Tutorial sobre Bancos de Dados Geográficos - GeoBrasil. INPE - Instituto Nacional de Pesquisas Espaciais, São José dos Campos, 104 p. 
REIS, Antônio Tarcísio da Luz \& LAY, Maria Cristina Dias (2006) - "Avaliação da qualidade de projetos - uma abordagem perceptiva e Cognitiva" "Evaluation of design quality - a perceptive and cognitive Approach". Ambiente Construído, ISSN 1415-8876, Vol. 6, № 3, 21-34. Disponível online na url: http://seer.ufrgs.br/ambienteconstruido/article/viewFile/3710/2057 (acedido em abril, 2013).

ROCHA, Isabel Amália Medero (2005) - O Espaço Arquitetônico entre o real e o Virtual. Simulação ou realidade? Universidade do Vale do Rio dos Sinos. Curso de Arquitetura e Urbanismo. Disponível online no endereço url: http://cumincades.scix.net/data/works/att/sigradi2005_517.content.pdf (acedido em maio de 2013).

SANTA ROSA, Antonio Nuno de Castro (2011) - Geogestão Dinâmica. Instituto de Geociências. Universidade de Brasília, Brasília-DF.

SERRA, Geraldo (1987) - O Espaço Natural e a Forma Urbana. Editora Nobel, São Paulo, 211 p.

SILVA, Gomes da \& GUERRA, Denise Sans (2012) - Reflexões sobre o Diálogo entre Espaços Físicos e o Cotidiano na Educação Infantil. GT-07, PUC-RJ - GT: Educação de Crianças de 0 a 6 Anos/No 07. PUC/Rio. Disponível online no endereço url: http://www.anped.org.br/reunioes/29ra/trabalhos/trabalho/ GT07-1891--Int.pdf (acedido em janeiro, 2013).

SOMMER, Robert (1973) - Espaço Pessoal: As Bases Comportamentais de Projetos e Planejamentos. Pedagógica e Universitária Ltda., São Paulo, 220 p.

SOMMER, Robert (2002) - "O desenvolvimento e a aplicação dos conceitos de espaço pessoal”, in DEL RIO, Vicente et al. (orgs.). Projeto do lugar - colaboração entre psicologia, arquitetura e urbanismo. Contra capa, Rio de Janeiro, 392 p.

UNIVERSIDADE DE BRASÍlIA (2006) - Manual do Sistema de Informação de Registro e Concessão de Uso - SIRC, Brasília-DF.

VEIGA, Ilma Passos Alencastro (2002) - Projeto político-pedagógico da escola: uma construção possível. Papirus, 14aㅡ ed., Campinas, 192 p. 
Série Documentos

Imprensa da Universidade de Coimbra

Coimbra University Press

2015

- U M

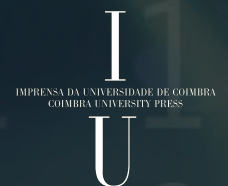

